\title{
An Autopsy Case of Fatal Methemoglobinemia due to Ingestion of Sodium Nitrite
}

Minori Nishiguchi", Hideyuki Nushida, Noriyuki Okudaira and Hajime Nishio

Department of Legal Medicine, Hyogo College of Medicine, Nishinomiya, Hyogo, Japan

*Corresponding author:Minori Nishiguchi, Department of Legal Medicine, Hyogo College of Medicine, Mukogawa-cho 1-1, Nishinomiya, Hyogo 663-8501, Japan, Tel: +81-798-45-6578; Fax: +81-798-49-3279; E-mail:m-nishig@hyo-med.ac.jp

Rec date: Oct 15, 2014 Acc date: Dec 06, 2014 Pub date: Dec 10, 2014

Copyright: @ 2014 Minori Nishiguchi. This is an open-access article distributed under the terms of the Creative Commons Attribution License, which permits unrestricted use, distribution, and reproduction in any medium, provided the original author and source are credited.

\begin{abstract}
We herein present an autopsy case of fatal methemoglobinemia due to suicidal ingestion of sodium nitrite. A man in his 30s who had exhibited mild depression was found dead in his house. A glass containing a white turbid solution and a suicide note were found on the table near the decedent. At autopsy, the lividity of the face and back was greenish gray, and the blood was tinted a chocolate brown color. Toxicological analysis of nitrite and nitrate using a colorimetric method showed that the nitrite concentrations were $<0.05$ and $0.09 \mu \mathrm{g} / \mathrm{mL}$ and that the nitrate concentrations were 71.69 and $83.48 \mu \mathrm{g} / \mathrm{mL}$ in the heart and femoral blood, respectively. Biochemical analysis after death showed that the level of methemoglobin was $83.4 \%$ by spectrophotometry. We conclude that the cause of death was severe methemoglobinemia following acute poisoning induced by sodium nitrite ingestion, although the blood nitrite concentration did not reach the fatal level.
\end{abstract}

Keywords: Nitrite; Nitrate; Fatal methemoglobinemia; Overdose; Toxicology

\section{Introduction}

Sodium nitrite has long been used as a color enhancer in cured meats and fishes, a preservative, and an antimicrobial agent worldwide $[1,2]$. Other, and is also used as an industrial chemical and therapeutic agent. Poisoning by sodium nitrite is an unexpected accident in many cases. In North American and European countries, where large amounts of sodium nitrite are added to food, many cases of methemoglobinemia caused by accidental ingestion or inhalation of nitrites have been reported [1-5]. In contrast, few cases of fatal poisoning by nitrites in food have been reported in Japan [6,7]. Small amounts of nitrite, as food additives, ingestion are not associated with poisoning symptoms, whereas acute exposure to excessive dosages may be associated with lethal symptoms such as methemoglobinemia.

Severe methemoglobinemia is caused by exposure to therapeutic agents and chemicals such as nitrogen oxide $[3,8,9]$ and chlorates [10-12], which oxidize hemoglobin into methemoglobin. Oxidizing drugs such as nitrites oxidize the $\mathrm{Fe}^{2+}$ of the hemoglobin to $\mathrm{Fe}^{3+}$ and convert hemoglobin to methemoglobin, which loses its ability to bind and transport oxygen. The methemoglobin level in humans is normally $<1 \%$; levels of $>70 \%$ can cause lethal tissue hypoxia $[7,13,14]$.

In most fatal cases of severe methemoglobinemia secondary to sodium nitrite ingestion, the serum nitrite concentration exceeds the lethal level. However, there is not the report of the deceased who died of fatal methemoglobinemia although the serum nitrite concentration did not reach the lethal level. We herein report an autopsy case of fatal poisoning by suicidal ingestion of a large amount of sodium nitrite in the form of a chemical food additive; death occurred despite the fact that the blood nitrite concentration was lower than the lethal level. Biochemical analysis showed high levels of methemoglobin in the blood.

\section{Materials and Methods}

\section{Case history}

A man in his 30s who had worked in a ham-processing factory was found dead in the left lateral position in his living room. He had vomited a large amount of stomach contents. A glass containing a white turbid solution and a suicide note were found on the table near the decedent. A plastic bag containing approximately $120 \mathrm{~g}$ of a white powder was found in the drawer of a chest in the living room. He had a medical history of mild depression, hypertension, and diabetes. $\mathrm{He}$ had attempted suicide a few months previously. To clarify the cause of death, a forensic autopsy was performed approximately $24 \mathrm{~h}$ after his death.

\section{Autopsy findings}

The decedent was $175 \mathrm{~cm}$ tall and weighed $121.0 \mathrm{~kg}$. The lividity of the face and back was greenish gray. External findings were unremarkable. Internally, however, both lungs (left, $475 \mathrm{~g}$; right, $555 \mathrm{~g}$ ) were slightly edematous. No bronchial foreign body was observed. The heart $(615 \mathrm{~g})$ contained approximately $650 \mathrm{~mL}$ of chocolate-brown colored blood and exhibited slight myocardial fibrosis and calcification. The coronary artery showed no abnormal findings, including stenosis. The brain $(1570 \mathrm{~g})$ showed no macroscopic abnormalities. Nitrite in blood samples is unstable at room temperature and is readily oxidized to nitrate [15]. Postmortem heart blood, femoral blood, and urine specimens were collected during autopsy and kept at $-80^{\circ} \mathrm{C}[16,17]$ for toxicological examination.

\section{Toxicological examination}

Quantification of the nitrite and nitrate concentrations in the heart and femoral blood were measured by a previously described colorimetric method [18,19] at the Forensic Science Research Center (Tokyo, Japan). Qualitative analysis of the white powder, vomited 
stomach contents, and glass of white turbid solution was performed by the Forensic Science Laboratory of Hyogo Prefectural Police Headquarters (Hyogo, Japan). Methemoglobinemia was measured with a portable oximeter (AVOXimeter 4000; A-VOX Systems, International Technidyne Corporation, NJ, USA) that was able to measure carboxyhemoglobin, oxyhemoglobin, and total hemoglobin. This oximeter measures the levels of these three types of hemoglobin by simultaneously monitoring seven wavelengths $(488,520,560,585$, 597, 622, and $672 \mathrm{~nm}$ ) [20]. The blood and urine samples were analyzed for ethanol by headspace gas chromatography (AutoSystem XL; PerkinElmer, Waltham, MA, USA). All organic compounds except the ionization materials were measured with a gas chromatographmass spectrometer (GCMS-QP2010; GC Solution system, Shimadzu, Kyoto, Japan) following liquid-liquid phase extraction with EXtrelut NT3 columns (Merck, Darmstadt, Germany).

\section{Results}

The results of the toxicological analysis of this case are presented in Table 1. Nitrite and nitrate was detected in heart and femoral blood, and the nitrite in neither blood sample reached lethal levels. Sodium nitrite was detected in the plastic bag containing white powder, vomited stomach contents, and glass of white turbid solution. Biochemical analysis showed that the methemoglobin level in the heart blood was $83.4 \%$ using the oximeter by spectrophotometry. No ethanol was detected in the blood or urine. Drug screening results using the Triage Drugs of Abuse Panel (Biosite Diagnostic Inc., San Diego, CA, USA) were negative.

\begin{tabular}{|l|l|l|}
\hline Concentration $(\boldsymbol{\mu g} / \mathrm{mL})$ & Nitrite & \multicolumn{1}{|c|}{ Nitrate } \\
\hline Heart blood & $<0.05$ & 71.69 \\
\hline Femoral blood & 0.09 & 83.48 \\
\hline
\end{tabular}

Table 1: Nitrite and nitrate concentrations in blood samples

\section{Discussion}

Nitrite is used to maintain the bright pink color of meat and suppresses the growth of microorganisms. It is a powerful drug; the median lethal dose of oral sodium nitrite is $71 \mathrm{mg} / \mathrm{kg}$ of body weight in humans. Nitrite as therapeutic agent and chemical oxidizes $\mathrm{Fe}^{2+}$ of hemoglobin to $\mathrm{Fe}^{3+}$ and produces methemoglobin, in turn promoting the process of methemoglobin production [14]. Methemoglobin is originally produced in the body from hemoglobin by auto-oxidation. However, NADH- and NADPH-methemoglobin reductase catalyze the process that reduces methemoglobin to hemoglobin and maintains the methemoglobin concentration at $<1 \%[7,13,14]$. After a large quantity of ingested nitrite or exposure to nitrite, the methemoglobin level increases to exceed the reduction ability of reductase. Methemoglobin is not capable of binding and transporting oxygen. Additionally, methemoglobinemia strengthens the bond between oxygen and the hemoglobin and decreases the oxygen supply in the tissues, resulting in a leftward shift of the oxygen dissociation curve. The decreased oxygen supply may cause a headache, cyanosis, breathing disorders, and death. The lethal blood methemoglobin level is generally $>70 \%[7,9,13]$.

Serum nitrite levels in previous reports of death following accidental or intentional ingestion of nitrite have showed levels of 0.55 to $13 \mu \mathrm{g} / \mathrm{mL}[9,21]$. A high methemoglobin level was detected in these cases, and the cause of death was methemoglobinemia. In the present case, the nitrite concentrations in the heart and femoral blood are presented in Table 1; they were lower than those previously reported. However, the ingestion of a large amount of nitrite causes death by induced methemoglobinemia in a very short time [9]. In addition, in some deaths due to sodium nitrite, the drug has been detected in gastric contents but not in other body fluids or tissues [22]. Therefore, if the presence of nitrite is suspected in the blood, determination of the methemoglobin level may be more important than the nitrite or nitrate level. In the present case, the level of methemoglobin was $83.4 \%$, which is higher than previously reported fatal levels $[6,7,8,21]$.

In this case, the concentrations of nitrate $(71.69$ and $83.48 \mu \mathrm{g} / \mathrm{mL}$ in the heart and femoral blood, respectively) were higher than those of nitrite (Table 1). Nitrite is converted to nitrate, which is incapable of oxidizing hemoglobin to methemoglobin in the body. The accidental ingestion of $75 \mathrm{~g}$ of sodium nitrate by one man resulted in gastrointestinal symptoms, but his methemoglobin levels were normal and he made an uneventful recovery [23].

In summary, we have presented the results of a postmortem examination of the heart and femoral blood after ingestion of sodium nitrite, which may have been obtained from the ham-processing factory where the deceased worked. This case of death of severe methemoglobinemia following acute poisoning by sodium nitrite is infrequency; the serum nitrite concentration dose did not reach the fatal level.

\section{Acknowledgments}

This study was supported in part by the Forensic Science Research Center and the Forensic Science Laboratory of Hyogo Prefectural Police Headquarters.

\section{References}

1. Cockburn A, Brambilla G, Fernández ML, Arcella D, Bordajandi LR, et al. (2013) Nitrite in feed: from animal health to human health. Toxicol Appl Pharmacol 270: 209-217.

2. Bacon R (1997) Nitrate preserved sausage meat causes an unusual food poisoning incident. Commun Dis Rep CDR Rev 7: R45-47.

3. Centers for Disease C, Prevention. Methemoglobinemia following unintentional ingestion of sodium nitrite -New York, 2002. MMWR Morbidity and mortality weekly report 2002;51: 639-42.

4. Faivre J, Faivre M, Klepping C, Roche L (1976) [Methemoglobinemias caused by ingestion of nitrites and nitrates]. Ann Nutr Aliment 30: 831-838.

5. Kennedy N, Smith CP, McWhinney P (1997) Faulty sausage production causing methaemoglobinaemia. Arch Dis Child 76: 367-368.

6. Saito T, Takeichi S, Yukawa N, Osawa M (1996) Fatal methemoglobinemia caused by liniment solutions containing sodium nitrite. J Forensic Sci 41: 169-171.

7. Saito T, Takeichi S, Osawa M, Yukawa N, Huang XL (2000) A case of fatal methemoglobinemia of unknown origin but presumably due to ingestion of nitrate. Int J Legal Med 113: 164-167.

8. Harvey M, Cave G, Chanwai G (2010) Fatal methaemoglobinaemia induced by self-poisoning with sodium nitrite. Emerg Med Australas 22: 463-465.

9. Standefer JC, Jones AM, Street E, Inserra R (1979) Death associated with nitrite ingestion: report of a case. J Forensic Sci 24: 768-771.

10. Kinoshita H, Yoshioka N, Kuse A, Nishiguchi M, Tanaka N et al., (2014) A fatal case of severe methemoglobinemia presumably due to chlorate ingestion. Soudni lekarstvi / casopis Sekce soudniho lekarstvi Cs lekarske spolecnosti J Ev Purkyne; 56: 43-4. 
Citation: Nishiguchi M, Nushida H, Okudaira N, Nishio H (2015) An Autopsy Case of Fatal Methemoglobinemia due to Ingestion of Sodium Nitrite. J Forensic Res 6: 1000262. doi:10.4172/2157-7145.1000262

Page 3 of 3

11. Couri D, Abdel-Rahman MS, Bull RJ (1982) Toxicological effects of chlorine dioxide, chlorite and chlorate. Environ Health Perspect 46: 13-17.

12. Steffen C, Seitz R (1981) Severe chlorate poisoning: report of a case. Arch Toxicol 48: 281-288.

13. Hall AH, Kulig KW, Rumack BH (1986) Drug- and chemical-induced methaemoglobinaemia. Clinical features and management. Med Toxicol 1: 253-260.

14. Percy MJ, McFerran NV, Lappin TR (2005) Disorders of oxidised haemoglobin. Blood Rev 19: 61-68.

15. Moshage H, Kok B, Huizenga JR, Jansen PL (1995) Nitrite and nitrate determinations in plasma: a critical evaluation. Clin Chem 41: 892-896.

16. Sato K, Tamaki K, Okajima H, Katsumata Y (1988) Long-term storage of blood samples as whole blood at extremely low temperatures for methemoglobin determination. Forensic Sci Int 37: 99-104.

17. Sato K, Tamaki K, Tsutsumi H, Okajima H, Katsumata Y (1990) Storage of blood for methemoglobin determination: comparison of storage with a cryoprotectant at -30 degrees $\mathrm{C}$ and without any additions at - 80 degrees C or -196 degrees C. Forensic Sci Int 45: 129-134.
18. Green LC, Wagner DA, Glogowski J, Skipper PL, Wishnok JS, et al. (1982) Analysis of nitrate, nitrite, and [15N]nitrate in biological fluids. Anal Biochem 126: 131-138.

19. Takahashi H, Nakanishi T, Nishimura $M$, Tanaka H, Yoshimura $M$ (1992) Measurements of serum levels of nitrate ions in men and women: implications of endothelium-derived relaxing factor in blood pressure regulation and atherosclerosis. Journal of cardiovascular pharmacology; 20 Suppl 12: 14-6.

20. Fujihara J, Kinoshita H, Tanaka N, Yasuda T, Takeshita H (2013) Accuracy and usefulness of the AVOXimeter 4000 as routine analysis of carboxyhemoglobin. J Forensic Sci 58: 1047-1049.

21. Gowans WJ (1990) Fatal methaemoglobinaemia in a dental nurse. A case of sodium nitrite poisoning. The British journal of general practice: the journal of the Royal College of General Practitioners; 40: 470-471.

22. Barton GM (1954) A fatal case of sodium nitrite poisoning. Lancet 266: 190-191.

23. Joosen D, Stolk L, Henry R (2014) A non-fatal intoxication with a highdose sodium nitrate. BMJ Case Rep 2014. 